\title{
Very low frequency of germline GPR101 genetic variation and no biallelic defects with AIP in a large cohort of patients with sporadic pituitary adenomas
}

\author{
Anne-Lise Lecoq 1,2,5, , Jérôme Bouligand 1,3,5,*, Mirella Hage 1,2,5, Laure Cazabat ${ }^{2}$, \\ Sylvie Salenave ${ }^{2}$, Agnès Linglart 1,4, Jacques Young ${ }^{1,2,5}$, Anne Guiochon-Mantel 1,3,5, \\ Philippe Chanson ${ }^{1,2,5}$ and Peter Kamenický 1,2,5
}

\begin{abstract}
${ }^{1}$ Faculté de Médecine Paris-Sud, Université Paris-Sud, Université Paris-Saclay, UMR-S1185, 94276 Le Kremlin Bicêtre, France, ${ }^{2}$ Assistance Publique-Hôpitaux de Paris, Hôpital de Bicêtre, Service d'Endocrinologie et des Maladies de la Reproduction, 94275 Le Kremlin-Bicêtre, France, ${ }^{3}$ Service de Génétique moléculaire, Pharmacogénétique et Hormonologie, 94275 Le Kremlin-Bicêtre, France, 'Service d'Endocrinologie Pédiatrique, 94275 Le Kremlin-Bicêtre, France and ${ }^{5}$ Institut National de la Santé et de la Recherche Médicale (INSERM) U1185, 94276 Le Kremlin-Bicêtre, France

${ }^{*}$ (A-L Lecoq and J Bouligand contributed equally to this work)
\end{abstract}

\author{
Correspondence \\ should be addressed \\ to P Kamenický \\ Email \\ peter.kamenicky@u-psud.fr
}

\begin{abstract}
Context: Recently, germline and somatic GPR101 p.(E308D) mutation was found in patients with isolated acromegaly. It is not known whether GPR101 point mutations are associated with other histological types of pituitary adenoma. Objective: We sought germline GPR101 mutations in patients with sporadic pituitary adenomas, and compared the phenotypes of GPR101 mutation carriers and AIP mutation carriers.

Design: An observational cohort study performed between 2007 and 2014 in a single referral center.

Participants: This prospective study involved 766 unselected patients (413 women) with sporadic pituitary adenomas of all histotypes.

Methods: Entire GPR101 and AIP coding sequence were screened for germline mutations.

Results: Twelve patients (1.6\%) were found to carry the GPR101 p.(E308D) mutation or rare GPR101 variants. The minor allele frequency of the GPR101 mutation and variants was higher in patients with pituitary adenomas than in unaffected individuals included in the Exome Aggregation Consortium database. Three of the six patients with the GPR101 p.(E308D) mutation had adult-onset acromegaly, two had adrenocorticotropin-secreting adenomas, and one had a nonfunctioning macroadenoma. Six patients carried rare GPR101 variants. Germline AIP mutations or rare AIP variants were identified in 32 patients (4.2\%). AIP mutation carriers were younger at diagnosis than GPR101 mutation carriers and non carriers. None of the patients harbored mutations in both the GPR101 and AIP genes.

Conclusion: Germline GPR101 mutations are very rare in patients with sporadic pituitary adenomas of various histotypes. No digenism with AIP was identified. Further studies are required to establish whether and how genetic variation in GPR101 gene contributes to pituitary tumorigenesis.
\end{abstract} Printed in Great Britain
Published by Bioscientifica Ltd. 


\section{Introduction}

The molecular mechanisms underlying pituitary tumorigenesis remain elusive. Very few pituitary adenomas occur as a component of hereditary syndromes such as MEN type 1 and 4, the Carney complex or in the absence of syndromic clinical features, familial isolated pituitary adenoma (FIPA). The vast majority of pituitary adenomas are sporadic (1). Recently, microduplications in chromosome region Xq26.3 were shown to cause very-young-onset $\mathrm{X}$-linked acrogigantism (X-LAG) in patients with growth hormone (GH)-secreting pituitary adenomas or hyperplasia $(2,3)$. The duplicated region in Xq26.3 contained four protein-coding genes, of which only GPR101 was frankly overexpressed in pituitary tumors from patients with X-LAG. GPR101 encodes an orphan G-protein-coupled receptor, even though recent in vitro data suggest that GPR101 mediates the biological effects of the GnRH-(1-5) pentapeptide (4). Both somatic and germline activating GPR101 p.(E308D) mutation was found in a large international cohort of patients with isolated acromegaly (2). In keeping with this finding, we reported in a Letter to the Editor the cases of three patients (1.1\%) with germline GPR101 p.(E308D) mutation, identified among 263 unselected acromegalic patients from our cohort (5).

It is unclear whether GPR101 mutations are associated with sporadic pituitary adenomas of other histological types. We therefore screened our entire cohort of 766 patients with sporadic pituitary adenomas for germline mutations of GPR101. We then analyzed the clinical and genetic characteristics of patients carrying the p.(E308D) mutation or previously unreported rare GPR101 variants.

Germline mutations in AIP (encoding the Arylhydrocarbon receptor-Interacting Protein) have been identified in patients with both familial $(6,7,8,9,10)$ and sporadic pituitary adenomas $(10,11,12,13,14)$. The penetrance of pituitary adenomas in AIP mutation carriers is low, especially in patients with no familial history $(1,10)$. We thus screened our cohort for AIP mutations in order to search for digenism with GPR101 variants that could account for the variable phenotype of AIP-mutated patients and influence the penetrance of pituitary adenomas in AIP mutation carriers.

\section{Patients and methods}

\section{Patients}

The cohort was prospectively constituted to evaluate the prevalence of AIP mutations in patients with sporadic pituitary adenomas. All patients seen in our referral center for pituitary adenomas between June 2007 and December 2014 were asked to participate. Based on clinical, biological and/or histological criteria, the patients were grouped into the following diagnostic categories: $\mathrm{GH}$-secreting adenomas, GH- and prolactin-secreting adenomas, prolactin-secreting adenomas, adrenocorticotrophin (ACTH)-secreting adenomas, nonfunctioning adenomas (including gonadotropin-secreting adenomas) and thyrotropin-secreting adenomas (including thyrotrophin (TSH)- and GH-secreting adenomas). Gigantism was defined by excessively rapid growth velocity for age in children or adolescents ( $>97$ th percentile), or a final height $>+2$ SD above normal for the French population, together with abnormal insulin-like growth factor 1 values for age and unsuppressed GH after an oral glucose tolerance test. Patients with MEN type 1 and type 4, the Carney complex, the McCune-Albright syndrome or $\mathrm{X}$-LAG were not enrolled, and samples from relatives of GPR101 or AIP mutation-positive simplex cases were not studied. Relevant clinical, biological, morphological and histological data were collected for all the patients. Based on pituitary magnetic resonance imaging, the adenomas were divided into microadenomas (larger diameter $<10$ $\mathrm{mm}$ ), macroadenomas (larger diameter between 10 and $39 \mathrm{~mm}$ ), and giant adenomas (larger diameter $>40 \mathrm{~mm}$ ). All the patients or their relatives signed informed consent forms approved by the local ethics committee.

\section{Genetic testing}

Genomic DNA was extracted from white blood cells either manually using the high salt method or by automated QIAsymphony SP instrument (Qiagen). We sequenced the entire coding sequence of the GPR101 gene using the following primers: A-forward GTGTTTCTTTTGTCACCAGCATAG and A-reverse GGGTCATCTTGGACGGGTA; B-forward TTAGCCTCACCCACCTGTTC, and B-reverse GCCCCTGGCCTCTACACTAC; C-forward AGGTGAGGTCAAGGCCAAG, and C-reverse AATGGTCTTGTGCATGTAGCC; D-forward CAAAGCTGCTAAAGTGATCTTCAT, and D-reverse TTAATGAATTGTGGGTCCATTG. The entire AIP coding region (exons 1-6) and intron-exon junctions were amplified and sequenced with primers described elsewhere (14). PCR and sequencing products were purified on a Biomek NXP-96 Laboratory Automation Workstation (Beckman Coulter, Villepinte, France) with Agencourt Ampure XP and Agencourt Cleanseq (Beckman 
Coulter Genomics, Danvers, MA, USA). Sequencing products were analyzed with an automated capillary sequencer (ABI PRISM 3730S Genetic Analyzer; Applied Biosystems). Electropherogram-derived sequences were compared with NCBI references for the GPR101 gene (NG_016367.1 RefSeqGene and NM_054021.1) and the AIP gene (NG_008969.1 RefSeq- Gene and NM_003977.2 transcript). All genetic abnormalities were confirmed by a second analysis. Screening for large deletion or duplication in AIP gene by multiplex ligation-dependent probe amplification (MLPA) was performed in patients with GH-secreting and mixt GH- and prolactin-secreting pituitary adenomas, who were younger than 40 years at diagnosis, using the SALSA MLPA kit P244 (MRC Holland, Amsterdam, The Netherlands). The promoter area of AIP was not analyzed. The presence of all new variants was verified in the Exome Aggregation Consortium (ExAC) database (http://exac.broadinstitute.org/). Only rare variants with minor allele frequencies $(\mathrm{MAF})<1 \%$ in unaffected individuals included in the ExAC database were considered for further analysis. In silico analysis of GPR101 and $A I P$ variants was performed with various algorithms contained in Alamut Mutation Interpretation Software (Interactive Bio Software, Rouen, France) in order to assess their impact at both the mRNA and protein levels. The new variants were classified as pathogenic, likely pathogenic, variants of uncertain significance (VUS) or likely benign, according to the standards and guidelines for the interpretation of sequence variants (15).

\section{Statistical analysis}

Continuous variables are reported as median (range). Allele frequencies and categorical variables were compared using the $\chi^{2}$ test. The nonparametric Mann-Whitney $U$-test or the Kruskal-Wallis test was used to analyze the quantitative data. Statistical significance was assumed when the $P$ value was $<0.05$. All statistical analyses were carried out using GraphPad Prism 5 Statistical Software (GraphPad Software Inc., La Jolla, CA, USA).

\section{Results}

\section{Study population}

Seven hundred seventy seven individuals were screened for germline GPR101 and AIP mutations. Eight patients with pituitary tumors in whom the diagnosis of pituitary adenoma could not be established because of a lack of clinical, biological and/or histological data were excluded from the analysis. Two acromegalic patients who were the members of a kindred with FIPA were also excluded, as was a sporadic giant with X-LAG. The study population thus consisted of 766 patients with sporadic pituitary adenomas, comprising 443 patients previously described in a study of germline AIP mutations in apparently sporadic pituitary adenomas (14), and 323 new patients. The characteristics of the cohort are shown in Table 1 . Thirty-eight patients were diagnosed in childhood or adolescence $(<18$ years). Among the patients with acromegaly, 22 patients had non-syndromic gigantism and 241 had adult-onset acromegaly due to pure GHsecreting or GH- and prolactin-cosecreting adenomas. Except for ACTH-secreting adenomas, macroadenomas predominated in patients with other histotypes.

\section{Patients with the GPR101 p.(E308D) mutation or rare GPR101 variants}

Twelve (1.6\%) of the 766 patients with pituitary adenomas were positive for the previously reported germline p.(E308D) mutation or for rare GPR101 variants. The clinical characteristics of these patients are shown in Table 2. Age at diagnosis did not differ between patients

Table 1 General description of the study population.

\begin{tabular}{l}
\hline Adenoma type \\
\hline Total \\
GH-secreting \\
GH- and prolactin-cosecreting \\
Prolactin-secreting \\
ACTH-secreting \\
Nonfunctioning \\
Thyotropin-secreting
\end{tabular}

\begin{tabular}{c}
\hline Number of patients \\
\hline 766 \\
218 \\
45 \\
256 \\
68 \\
165 \\
14 \\
\hline
\end{tabular}

\begin{tabular}{c}
\hline Number of females $n(\%)$ \\
\hline $413(54)$ \\
$100(46)$ \\
$16(36)$ \\
$164(64)$ \\
$52(76)$ \\
$77(47)$ \\
$4(29)$ \\
\hline
\end{tabular}

\begin{tabular}{c}
\hline $\begin{array}{c}\text { Age at diagnosis } \\
\text { median (range) }\end{array}$ \\
\hline $39(11-87)$ \\
$42(15-77)$ \\
$36(14-66)$ \\
$29(13-78)$ \\
$38(11-73)$ \\
$55(14-87)$ \\
$40(22-75)$ \\
\hline
\end{tabular}

\begin{tabular}{c}
\hline $\begin{array}{c}\text { Macroadenoma } \\
n(\%)\end{array}$ \\
\hline $563(73)$ \\
$172(79)$ \\
$44(98)$ \\
$151(59)$ \\
$24(35)$ \\
$159(96)$ \\
$13(93)$
\end{tabular}

${ }^{\text {a}}$ Nonfunctioning pituitary adenomas include gonadotropin-secreting adenomas. 
Table 2 Clinical, morphological and genetic characteristics of the patients with the GPR101 p.(E308D) mutation or rare GPR101 variants.

\begin{tabular}{|c|c|c|c|}
\hline Patient No. & Adenoma type & Sex & $\begin{array}{c}\text { Age at } \\
\text { diagnosis (years) }\end{array}$ \\
\hline $1^{a}$ & GH-secreting & $\mathrm{F}$ & 48 \\
\hline $2^{a}$ & GH-secreting & $\mathrm{M}$ & 45 \\
\hline $3^{a}$ & GH-secreting & $\mathrm{F}$ & 41 \\
\hline $4^{a}$ & GH-secreting & $\mathrm{M}$ & 44 \\
\hline 5 & Prolactin-secreting & $\mathrm{F}$ & 33 \\
\hline 6 & Prolactin-secreting & $\mathrm{F}$ & 29 \\
\hline 7 & ACTH-secreting & $\mathrm{F}$ & 26 \\
\hline 8 & ACTH-secreting & $\mathrm{F}$ & 21 \\
\hline 9 & ACTH-secreting & $\mathrm{M}$ & 38 \\
\hline 10 & Nonfunctioning & $\mathrm{M}$ & 71 \\
\hline 11 & Nonfunctioning & $\mathrm{M}$ & 35 \\
\hline 12 & TSH and $\mathrm{GH}$-secreting & $\mathrm{M}$ & 32 \\
\hline
\end{tabular}

\begin{tabular}{|c|c|}
\hline $\begin{array}{l}\text { Symptoms at } \\
\text { diagnosis }\end{array}$ & $\begin{array}{l}\text { Adenoma } \\
\text { size }\end{array}$ \\
\hline Acromegaly + HPT & Macro \\
\hline Acromegaly & Macro \\
\hline Mild acromegaly & Micro \\
\hline Acromegaly & Macro \\
\hline Amenorrhea & Macro \\
\hline Primary amenorrhea & Micro \\
\hline Cushing's syndrome & Micro \\
\hline Cushing's syndrome & Micro \\
\hline Visual defects & Giant \\
\hline Panhypopituitarism & Macro \\
\hline Pituitary apoplexy & Macro \\
\hline Visual defects & Macro \\
\hline
\end{tabular}

\begin{tabular}{|c|c|}
\hline $\begin{array}{c}\text { Mutation or } \\
\text { variant }\end{array}$ & $\begin{array}{c}\text { Protein } \\
\text { consequence }\end{array}$ \\
\hline c. $924 \mathrm{G}>\mathrm{C}$ & p.(E308D) \\
\hline c. $924 \mathrm{G}>\mathrm{C}$ & p.(E308D) \\
\hline c. $924 \mathrm{G}>\mathrm{C}$ & p.(E308D) \\
\hline c. $1098 C>A$ & p.(D366E) \\
\hline c. $974 \mathrm{C}>\mathrm{T}$ & p.(T325I) \\
\hline c. $1294 C>T$ & p. (P432S) \\
\hline$c .365 T>Y$ & p. (I122T) \\
\hline c. $924 \mathrm{G}>\mathrm{C}$ & p.(E308D) \\
\hline c. $924 \mathrm{G}>\mathrm{C}$ & p.(E308D) \\
\hline C. $924 \mathrm{G}>\mathrm{C}$ & p.(E308D) \\
\hline c. $1074 C>T$ & p. $(=)$ \\
\hline c. $354 C>T$ & p. $(=)$ \\
\hline
\end{tabular}

HPT, hyperparathyroidism. Genetic analysis in patient number 1 did not identify any germline mutations or deletions in MEN1 and CDKN1B genes. apreviously reported cases $(2,5)$.

with and without GPR101 mutation (36 years (21-71) vs 39 years (11-87), not significant). In silico prediction of the pathogenicity of the rare GPR101 variants is shown in Table 3. The MAFs of the p.(E308D) mutant and of the rare GPR101 variants are shown in Table 4. The overall MAF of the GPR101 p.(E308D) mutation and variants was higher in patients with pituitary adenomas than in unaffected individuals included in the ExAC database.

Six patients had the germline p.(E308D) mutation. Three of them (patients number 1, 2 and 3 in Table 2) had adult-onset sporadic acromegaly due to a pure GH-secreting adenoma and have been described elsewhere $(2,5)$. Regarding the two patients with ACTH-secreting adenomas and p.(E308D) mutation, the female patient had typical early-onset Cushing's disease and a microadenoma, whereas the male patient had a giant pituitary adenoma responsible for visual impairment but only subclinical hypercortisolism. One p.(E308D)-carrying male patient had a nonfunctioning macroadenoma revealed by panhypopituitarism.
Six patients had rare germline GPR101 variants. One patient with sporadic acromegaly (patient number 4 in Table 2) presented with the p.(D366E) variant and has been reported in (5). This likely pathogenic variant is not reported in the ExAC database. In addition, we found four rare GPR101 variants c.354C $>$ T, p. $(=)$, p.(I122T), p.(T325I) and c.1074C $>$ T, p. $(=)$, also not reported in the ExAC database (Table 3). The silent variant c.1074C > T, p. $(=)$ is known in NCBI as \#rs537038614, but data on MAF are not available. Finally, the p.(P432S) variant is known as \#rs114879480 in NCBI and is reported in the ExAC database, but its MAF was higher in patients with prolactinomas than in unaffected individuals (Table 4). Of note, this likely pathogenic variant was identified in a patient with early-onset prolactinoma and primary amenorrhea (Table 2). Further, the likely pathogenic variant p.(I122T) was identified in a young patient with Cushing's syndrome and the silent variant c.354C $>\mathrm{T}, \mathrm{p} .(=)$ was identified in a patient with a mixt TSH- and GH-secreting adenoma. The missense variants p.(I122T), p.(T325I),

Table 3 In silico prediction of the pathogenicity of the new rare GPR101 variants.

\begin{tabular}{l} 
Variant \\
\hline C. $354 \mathrm{C}>\mathrm{T}$ \\
C. $365 \mathrm{~T}>\mathrm{Y}$ \\
c. $974 \mathrm{C}>\mathrm{Y}$ \\
c. $1074 \mathrm{C}>\mathrm{T}$ \\
c. $1098 \mathrm{C}>\mathrm{A}$ \\
c. $1294 \mathrm{C}>\mathrm{T}$ \\
\hline
\end{tabular}

\begin{tabular}{l} 
Protein-level consequence \\
\hline p. $(=)$ \\
p. $(I 122 \mathrm{~T})$ \\
p. $(\mathrm{T} 325 \mathrm{I})$ \\
p. $(=)$ \\
p.(D366E) \\
p. (P432S)
\end{tabular}

\begin{tabular}{l} 
Location in protein \\
\hline ICL2 \\
TM3 \\
ICL3 \\
ICL3 \\
ICL3 \\
ECL3
\end{tabular}

\begin{tabular}{l} 
Pathogenicity \\
\hline VUS \\
Likely pathogenic \\
VUS \\
VUS \\
Likely pathogenic \\
Likely pathogenic \\
\hline
\end{tabular}

\begin{tabular}{l}
\hline Conservation \\
\hline Yes \\
Yes \\
Yes \\
Yes \\
Yes \\
Yes
\end{tabular}

ICL2, intracellular loop 2; TM3, 3rd transmembrane segment; ICL3, intracellular loop 3; ECL3, extracellular loop 3; VUS, variants of uncertain significance. 
Table 4 Minor allele frequencies of the p.(E308D) GPR101 mutation and original rare GPR101 variants identified in this cohort of patients with sporadic pituitary adenomas.

\begin{tabular}{|c|c|}
\hline $\begin{array}{l}\text { Mutation or } \\
\text { variant }\end{array}$ & $\begin{array}{l}\text { Protein } \\
\text { consequence }\end{array}$ \\
\hline $\begin{array}{l}\text { c. } 354 C>T \\
\text { c. } 365 T>Y \\
c .924 G>C\end{array}$ & $\begin{array}{l}\text { p. }(=) \\
\text { p.(I122T) } \\
\text { p.(E308D) }\end{array}$ \\
\hline $\begin{array}{l}\text { C. } 974 C>Y \\
\text { C. } 1074 C>T \\
\text { C. } 1098 C>A \\
\text { C. } 1294 C>T \\
\text { All variants }\end{array}$ & $\begin{array}{l}\text { p. (T325I) } \\
\text { p. }(=) \\
\text { p.(D366E) } \\
\text { p.(P432S) }\end{array}$ \\
\hline
\end{tabular}

\begin{tabular}{l} 
Adenoma type \\
\hline TSH and GH-secreting \\
ACTH-secreting \\
GH-secreting \\
ACTH-secreting \\
Nonfunctioning \\
Total \\
Prolactin-secreting \\
Nonfunctioning \\
GH-secreting \\
Prolactin-secreting
\end{tabular}

\begin{tabular}{c}
$\begin{array}{c}\text { Number of variant } \\
\text { carriers }\end{array}$ \\
\hline 1 \\
1 \\
3 \\
2 \\
1 \\
6 \\
1 \\
1 \\
1 \\
1 \\
12 \\
\hline
\end{tabular}

\begin{tabular}{c}
\hline $\begin{array}{c}\text { Allele } \\
\text { frequency (\%) }\end{array}$ \\
\hline 5.56 \\
0.83 \\
0.94 \\
1.67 \\
0.41 \\
0.51 \\
0.24 \\
0.41 \\
0.31 \\
0.24 \\
1.02 \\
\hline
\end{tabular}

$P$ value vs general population

NR, $<0.0001$

$\mathrm{NR},<0.0001$

0.09

0.0199

0.90

0.42

$N R,<0.0001$

$\mathrm{NR},<0.0001$

$N R,<0.0001$

0.0488

0.0013

$\mathrm{NR}$, not reported in the EXAC database.

p.(D366E) and p.(P432S) affect highly conserved amino acids (data not shown).

\section{Patients with AIP mutations or rare AIP variants}

Germline AIP mutations or rare variants were identified in $32(4.2 \%)$ of the 766 patients with pituitary adenomas. Sixteen AIP mutation carriers have previously been reported in our study of 443 patients with sporadic pituitary adenomas (14). Among the 16 new patients with AIP mutations, three had pathogenic and four likely pathogenic AIP mutations, seven had VUS, and two had likely benign AIP variants (Table 5). Altogether, we identified 25 different $A I P$ mutations or rare variants in our cohort, five of which are new (Table 5).

Patients with AIP mutations were younger at diagnosis than both patients without AIP mutations and patients with GPR101 mutations (26 years (11-70) vs 40 years (1387 ), $P<0.0001$ and vs 36 years (21-71), $P=0.0117$ ) (Fig. 1 ). Among patients with acromegaly, those with AIP mutations were younger at diagnosis than those without AIP mutations (19 years (14-42) vs 40 years (14-77); $P=0.0009$ ). Six of the 10 AIP mutation carriers with $\mathrm{GH}$-secreting or $\mathrm{GH}$ - and prolactin-secreting adenomas

Table 5 Clinical, morphological and genetic characteristics of previously unreported patients with AIP mutations or rare AIP variants.

\begin{tabular}{|c|c|c|c|c|c|c|c|}
\hline Patient No. & Adenoma type & Sex & $\begin{array}{c}\text { Age at diagnosis } \\
\text { (years) }\end{array}$ & $\begin{array}{l}\text { Adenoma } \\
\text { size }\end{array}$ & $\begin{array}{l}\text { Mutationor } \\
\text { variant }\end{array}$ & Protein & Pathogenicity \\
\hline 1 & $\begin{array}{l}\text { GH- and prolactin- } \\
\text { cosecreting }\end{array}$ & $\mathrm{F}$ & 42 & Macro & c. $2 \mathrm{~T}>\mathrm{C}$ & p.? & Pathogenic \\
\hline 2 & GH-secreting & $\mathrm{M}$ & 17 & Giant & $c * 14 C>A$ & p.? & Likely benign \\
\hline 3 & ACTH-secreting & $\mathrm{F}$ & 40 & Macro & c. $26 \mathrm{G}>\mathrm{A}$ & p.(R9Q) & VUS \\
\hline 4 & ACTH-secreting & $\mathrm{F}$ & 11 & Micro & c. $47 \mathrm{G}>\mathrm{A}$ & p. $(\mathrm{R} 16 \mathrm{H})$ & Likely benign \\
\hline 5 & Prolactin-secreting & $\mathrm{M}$ & 46 & Macro & c. $100-6 C>A$ & p.? & VUS $^{a}$ \\
\hline 6 & Prolactin-secreting & $\mathrm{F}$ & 29 & Macro & c. $100-18 C>T$ & p.? & Likely pathogenic \\
\hline 7 & Prolactin-secreting & $\mathrm{M}$ & 23 & Macro & c. $382 \mathrm{C}>\mathrm{T}$ & p.(R128C) & VUS $^{a}$ \\
\hline 8 & Prolactin-secreting & $\mathrm{M}$ & 37 & Macro & c. $382 C>T$ & p.(R128C) & VUS $^{a}$ \\
\hline 9 & Nonfunctioning & $\mathrm{F}$ & 26 & Giant & c. $382 C>T$ & p. (R128C) & VUS $^{a}$ \\
\hline 10 & Prolactin-secreting & $\mathrm{F}$ & 26 & Micro & c. $591 \mathrm{G}>\mathrm{A}$ & p.(E197=) & Likely pathogenic \\
\hline 11 & $\begin{array}{l}\text { GH- and prolactin- } \\
\text { cosecreting }\end{array}$ & $\mathrm{M}$ & 16 & Macro & c.646G $>\mathrm{T}$ & p. $\left(E 216^{*}\right)$ & Pathogenic \\
\hline 12 & Prolactin-secreting & $\mathrm{F}$ & 32 & Macro & c.753G $>A$ & p. $(\mathrm{L} 251=)$ & VUS $^{a}$ \\
\hline 13 & Prolactin-secreting & $\mathrm{M}$ & 17 & Macro & c. $772 C>T$ & p.(L258F) & Likely pathogenic $^{a}$ \\
\hline 14 & Nonfunctioning & $\mathrm{M}$ & 48 & Giant & C.896C $>\mathrm{T}$ & p.(A299V) & VUS \\
\hline 15 & Prolactin-secreting & $\mathrm{M}$ & 36 & Micro & C. $911 \mathrm{G}>\mathrm{A}$ & p.(R304Q) & Pathogenic \\
\hline 16 & Nonfunctioning & $\mathrm{M}$ & 70 & Macro & c. $973 C>A$ & p. $($ R325 =) & VUS $^{a}$ \\
\hline
\end{tabular}




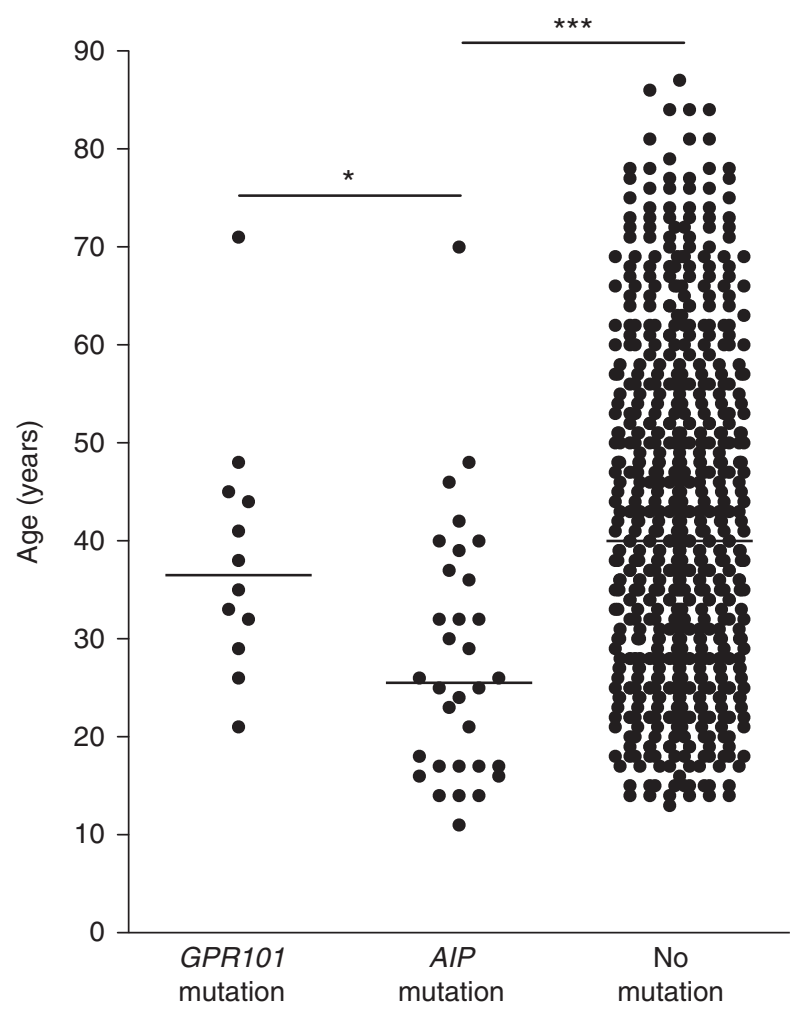

Figure 1

Age at diagnosis among 766 patients with sporadic pituitary adenomas, according to GPR101 and AIP mutation status. Median age at diagnosis is indicated by lines. ${ }^{*} P<0.05$; $* * * P<0.001$

were giants, compared with 16 giants among 253 AIP mutation-negative acromegalic patients $(P<0.0001)$. Nine of the ten $A I P$ mutation-positive acromegalic patients were males, compared with 138 males among 253 AIP mutation-negative acromegalic patients $(P=0.0268)$. None of the 766 patients harbored germline mutations in both the GPR101 and AIP genes.

\section{Discussion}

We describe the results of genetic screening for germline GPR101 mutations in the largest reported cohort of unselected patients with sporadic pituitary adenomas managed in a tertiary care center for pituitary diseases. For the first time, we report that the GPR101 p.(E308D) mutation and rare GPR101 variants are not restricted to patients with sporadic acromegaly but also occur in a small fraction of patients with sporadic pituitary adenomas that are not GH-secreting. We identified the p.(E308D) mutation in two simplex patients with ACTH-secreting pituitary adenomas and one patient with a nonfunctioning pituitary adenoma. In addition, we found original rare GPR101 variants in one patient with acromegaly, two patients with prolactin-secreting adenomas, one patient with Cushing's disease, one patient with a TSH- and GH-cosecreting adenoma and one patient with a nonfunctioning pituitary adenoma. Genetic screening for germline AIP mutations, conducted in parallel, identified new AIP mutation-positive patients and allowed us to analyze phenotypic differences between GPR101 and AIP mutation carriers.

The overall minor allelic frequency of the GPR101 p.(E308D) mutation and the rare GPR101 variants was higher in our cohort than in the ExAC database, which contains sequence data for about 61500 unrelated and apparently unaffected individuals. However, germline GPR101 genetic variation was very rare in this large cohort of patients with sporadic pituitary adenomas and therefore does not seem to have major pathophysiological significance for pituitary tumorigenesis.

The GPR101 p.(E308D) substitution is considered to be a pathogenic gain-of-function mutation, as overexpression of the p.(E308D) mutant in rat GH3 cells affects cell proliferation and GH secretion (2). However, overexpression of the p.(E308D) mutant did not result in a stronger cyclic AMP response elements activation than over-expression of the non-mutant GPR101 (2). In addition, it should be noted that p.(E308D) is also present in unaffected persons, with an allelic frequency of $0.36 \%$ according to the ExAC database (16). In our cohort, the p.(E308D) allele was over-represented in patients with ACTH-secreting adenomas. A similar trend towards a higher MAF was also observed in patients with GH-secreting adenomas but it did not reach statistical significance. A study of thousands rather than hundreds of patients would be necessary to determine the true importance of p.(E308D) in the pathophysiology of sporadic pituitary adenomas. Indeed, the reported lack of the p.(E308D) mutation in FIPA families (2) could be due to an inadequate sample size.

The phenotype of our GPR101 mutation-positive patients was variable and markedly different from that of the AIP mutation carriers. Half the carriers of the GPR101 mutant or variants were women. Likewise, half the GPR101 mutation-positive acromegalic patients were female, contrasting with the reported male predominance among AIP mutation-positive patients with sporadic acromegaly (1). However, in contrast to previous reports, in a recent study from a large international cohort there 
was no predominance of male patients among the AIP mutation positive familial cases (10). Age at diagnosis did not differ between GPR101 mutation-positive and -negative patients, whereas AIP mutation carriers were diagnosed at a younger age than non carriers (Fig. 1). In particular, GH excess was diagnosed after the age of 40 years in all four of our GPR101 mutation-positive acromegalic patients, whereas most AIP-mutated acromegalic patients are diagnosed before the age of 30 years (1). None of these four patients had GH- and prolactincosecreting adenomas, whereas this type of adenoma is frequently observed in AIP mutation-positive acromegalic patients (1). Unlike patients with AIP mutations, none of our 22 patients with sporadic non-syndromic gigantism harbored germline GPR101 mutations. Childhood onset of GH excess seems to require GPR101 gene overexpression rather than just its activation by a point mutation (2). Given the variable clinical features of GPR101 mutationpositive patients with sporadic pituitary adenomas, clinical findings cannot help to identify potential mutation carriers.

The low penetrance of sporadic pituitary adenomas and their variable clinical features among AIP mutation carriers suggests the involvement of other disease-modifying genes. None of the patients screened here harbored germline mutations in both the GPR101 and AIP genes, but the low frequency of GPR101 and AIP mutations in this cohort means that digenism cannot be ruled out. Trivellin et al. (2) reported that at least one GPR101 mutation-positive patient had a somatic GPR101 mutation in the adenoma but no germline mutation. Somatic GPR101 mutations might thus have a disease-modifying role in AIP-mutated pituitary adenomas $(1,10)$.

This study has several limitations. As already mentioned, recruitment of a larger population through international collaboration would enable the identification of more mutation carriers and provide a more comprehensive analysis of their phenotype. As our cohort was composed only of patients who had a hospital workup, many patients only seen in an outpatient clinic were excluded, explaining why microprolactinomas were underrepresented. Finally, functional in vitro studies would be necessary to confirm the pathogenicity of the rare GPR101 and AIP variants predicted by in silico analysis.

In conclusion, genetic screening for GPR101 mutations in the largest reported single-center cohort of patients with sporadic pituitary adenomas of various histological types showed a very low prevalence of GPR101 germline mutation and rare variants. The phenotype of GPR101 mutation-positive patients was variable and differed from that of AIP mutationpositive patients. None of the patients harbored germline mutations in both the GPR101 and AIP genes. Whether and how germline genetic variation in GPR101 contributes to pituitary tumorigenesis remains to be further investigated.

\section{Declaration of interest}

The authors declare that there is no conflict of interest that could be perceived as prejudicing the impartiality of the research reported.

\section{Funding}

A-L Lecoq was the recipient of a Poste d'Accueil INSERM and a grant from Association de Recherche contre le Cancer (ARC). P Kamenický was the recipient of a Contrat d'Interface INSERM.

\section{Acknowledgements}

We are indebted to Elodie Dupuis and Zaina Ait Arkoub for excellent technical assistance and to the nursing staff of Service d'Endocrinologie of Hôpital Bicêtre.

\section{References}

1 Lecoq A-L, Kamenický P, Guiochon-Mantel A \& Chanson P. Genetic mutations in sporadic pituitary adenomas - what to screen for? Nature Reviews Endocrinology 201511 43-54. (doi:10.1038/nrendo.2014.181)

2 Trivellin G, Daly AF, Faucz FR, Yuan B, Rostomyan L, Larco DO, Schernthaner-Reiter MH, Szarek E, Leal LF, Caberg J-H et al. Gigantism and acromegaly due to Xq26 microduplications and GPR101 mutation. New England Journal of Medicine 2014371 2363-2374. (doi:10.1056/ NEJMoa1408028)

3 Beckers A, Lodish MB, Trivellin G, Rostomyan L, Lee M, Faucz FR, Yuan B, Choong CS, Caberg J-H, Verrua E et al. X-linked acrogigantism syndrome: clinical profile and therapeutic responses. Endocrine-Related Cancer 201522 353-367. (doi:10.1530/ERC-15-0038)

4 Cho-Clark M, Larco DO, Semsarzadeh NN, Vasta F, Mani SK \& Wu TJ. GnRH-(1-5) transactivates EGFR in Ishikawa human endometrial cells via an orphan G protein-coupled receptor. Molecular Endocrinology 2014 28 80-98. (doi:10.1210/me.2013-1203)

5 Kamenický P, Bouligand J \& Chanson P. Gigantism, acromegaly, and GPR101 mutations. New England Journal of Medicine 20153721264. (doi:10.1056/NEJMc1500340\#SA1)

6 Vierimaa O, Georgitsi M, Lehtonen R, Vahteristo P, Kokko A, Raitila A, Tuppurainen K, Ebeling TML, Salmela PI, Paschke R et al. Pituitary adenoma predisposition caused by germline mutations in the AIP gene. Science 2006312 1228-1230. (doi:10.1126/science.1126100)

7 Daly AF, Vanbellinghen J-F, Khoo SK, Jaffrain-Rea M-L, Naves LA, Guitelman MA, Murat A, Emy P, Gimenez-Roqueplo A-P, Tamburrano $\mathrm{G}$ et al. Aryl hydrocarbon receptor-interacting protein gene mutations in familial isolated pituitary adenomas: analysis in 73 families. Journal of Clinical Endocrinology and Metabolism 200792 1891-1896. (doi:10.1210/jc.2006-2513)

8 Leontiou CA, Gueorguiev M, van der Spuy J, Quinton R, Lolli F, Hassan S, Chahal HS, Igreja SC, Jordan S, Rowe J et al. The role of the aryl hydrocarbon receptor-interacting protein gene in familial and sporadic 
pituitary adenomas. Journal of Clinical Endocrinology and Metabolism 200893 2390-2401. (doi:10.1210/jc.2007-2611)

9 Daly AF, Tichomirowa MA, Petrossians P, Heliövaara E, Jaffrain-Rea M-L, Barlier A, Naves LA, Ebeling T, Karhu A, Raappana A et al. Clinical characteristics and therapeutic responses in patients with germ-line AIP mutations and pituitary adenomas: an international collaborative study. Journal of Clinical Endocrinology and Metabolism 201095 E373-E383. (doi:10.1210/jc.2009-2556)

10 Hernández-Ramírez LC, Gabrovska P, Dénes J, Stals K, Trivellin G, Tilley D, Ferraù F, Evanson J, Ellard S, Grossman AB et al. Landscape of familial isolated and young-onset pituitary adenomas: prospective diagnosis in AIP mutation carriers. Journal of Clinical Endocrinology and Metabolism 2015100 E1242-E1254. (doi:10.1210/jc.2015-1869)

11 Barlier A, Vanbellinghen J-F, Daly AF, Silvy M, Jaffrain-Rea M-L, Trouillas J, Tamagno G, Cazabat L, Bours V, Brue T et al. Mutations in the aryl hydrocarbon receptor interacting protein gene are not highly prevalent among subjects with sporadic pituitary adenomas. Journal of Clinical Endocrinology and Metabolism 200792 1952-1955. (doi:10.1210/ jc.2006-2702)

12 Cazabat L, Libè R, Perlemoine K, René-Corail F, Burnichon N, GimenezRoqueplo A-P, Dupasquier-Fediaevsky L, Bertagna X, Clauser E, Chanson $\mathrm{P}$ et al. Germline inactivating mutations of the aryl hydrocarbon receptor-interacting protein gene in a large cohort of sporadic acromegaly: mutations are found in a subset of young patients with macroadenomas. European Journal of Endocrinology 2007 157 1-8. (doi:10.1530/EJE-07-0181)

13 Tichomirowa MA, Barlier A, Daly AF, Jaffrain-Rea M-L, Ronchi C, Yaneva M, Urban JD, Petrossians P, Elenkova A, Tabarin A et al. High prevalence of AIP gene mutations following focused screening in young patients with sporadic pituitary macroadenomas. European Journal of Endocrinology 2011165 509-515. (doi:10.1530/EJE-11-0304)

14 Cazabat L, Bouligand J, Salenave S, Bernier M, Gaillard S, Parker F, Young J, Guiochon-Mantel A \& Chanson P. Germline AIP mutations in apparently sporadic pituitary adenomas: prevalence in a prospective single-center cohort of 443 patients. Journal of Clinical Endocrinology and Metabolism 201297 E663-E670. (doi:10.1210/jc.2011-2291)

15 Richards S, Aziz N, Bale S, Bick D, Das S, Gastier-Foster J, Grody WW, Hegde M, Lyon E, Spector E et al. Standards and guidelines for the interpretation of sequence variants: a joint consensus recommendation of the American College of Medical Genetics and Genomics and the Association for Molecular Pathology. Genetics in Medicine 201517 405-424. (doi:10.1038/gim.2015.30)

16 Roohi J. Gigantism, acromegaly, and GPR101 mutations. New England Journal of Medicine 2015372 1264-1265. (doi:10.1056/NEJMc1500340)

Received 22 October 2015

Revised version received 2 January 2016

Accepted 20 January 2016 